\title{
Review on Evaluation on Mobile Generation Technology
}

\author{
C. Devasenapathi ${ }^{1 *}$, R. Arul arumugam ${ }^{2}$, B. Reuben ${ }^{3}$ \\ ${ }^{*}{ }_{1,2}$ Assistant Professor, Department of ECE, Annapoorna Engineering College, Salem, \\ ${ }^{3}$ Mahendra Institute of Technology Engineering, Namakkal
}

*Corresponding Author: C. Devasenapathi, Assistant Professor, Department of ECE, Annapoorna Engineering College, Salem, India.

\begin{abstract}
Since from the most recent couple of years look into innovation will open another time in versatile correspondence frameworks, the innovation goes delicate and basic for the general population to utilize various capacities with a solitary shrewd gadget. A standout amongst the best precedents is the remote versatile interchanges. The advancements of portable correspondences are quickly changing from $1 G$ to $5 G$. Is the correspondence frameworks has been a move from landline to cell versatile communication, bringing about Network engineering Planning and Optimization related administrations coming in to sharp core interest. The paper is especially intended to present the basic remote portable correspondences for future or cutting edge Technology. It gives a diagram of present and future patterns in the territories of remote versatile correspondences with various applications.
\end{abstract}

\section{INTRODUCTION}

Remote correspondence began from 1970s and it was persistently moved up to 5G.That is in next four decades, a portable remote innovation has advanced from $1 \mathrm{G}$ to $5 \mathrm{G}$ ages. Fifth era remote versatile correspondence frameworks offer extremely high transmission capacity that client never experienced and it gives new propelled highlights which makes it most dominant and in enormous interest later on .The present patterns of various remote and versatile interchanges advances are available, for example, third era portable systems

(UMTS-Universal Mobile Telecommunication framework with CDMA2000), fourth era versatile innovation LTE (Long Time Evolution), WiMAX, just as sensor and individual territory systems (for example Bluetooth). Figure1 demonstrates the development of portable correspondence frameworks with more administrations, information, use and advantages to the forthcoming age over 4G.5G will be more intelligent innovation without any limits and to interconnect the entire world unbounded.

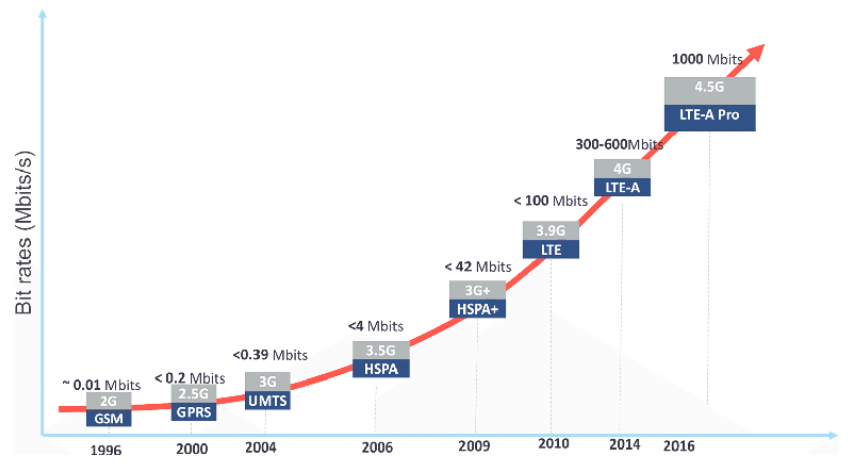

Figure1. Evolution of Mobile Communication Systems

The future remote correspondence framework is fifth era remote versatile mixed media web systems can be totally remote correspondence without confinement, which makes flawless remote genuine world - World Wide Wireless Web (WWWW). That fifth era depends on 4G advancements. The fifth remote portable web systems are genuine remote world which will be bolstered by LAS-CDMA (Large Area Synchronized Code-Division Multiple Access), OFDM (Orthogonal recurrence division 
multiplexing), MCCDMA (Multi-Carrier Code Division Multiple Access), UWB (Ultra-wideband), Network-LMDS (Local Multipoint Distribution Service), and IPv6. Fifth era innovations offers gigantic information abilities and unlimited assemble volumes and unbounded information communicate inside most recent versatile working framework. Fifth era should have an essential effect and add more administrations and advantages to the world over fourth era. Fifth era ought to be progressively wise innovation that interconnects the whole world unbounded. This age is relied upon to be discharged around 2020. The universe of general, continuous access to data, excitement and correspondence will open new measurement to our lives and change our way of life altogether.

\section{EVOLUTION}

Remote portable correspondence framework has turned out to be progressively famous because of quick changes in versatile innovation. Quick improvement of remote correspondence frameworks are because of high increment in telecoms clients. The transformation of versatile interchanges is from $1 \mathrm{G}$-the original, 2G-the second era, 3G-the third era, 4G-the fourth era, 5G-the fifth era.

\subsection{Original (1G)}

The original of versatile correspondence innovation rose in 1980s. The original versatile correspondence framework utilized simple transmission of discourse flag administrations. In the year 1979, the principal cell framework on the planet worked by Nippon Telephone and Telegraph (NTT) in Tokyo, Japan. Around then the most well known simple frameworks were Nordic Mobile Telephones (NMT) and Total Access Communication Systems (TACS), some other simple frameworks likewise presented in 1980s over the Europe. The principle downside of the original is those frameworks offered handover and meandering abilities yet cell systems were not able interoperate between the nations. In the year 1982s Advanced Mobile Phone System (AMPS) was propelled in United States. AMPS and TACS utilize the Frequency Modulation (FM) method and recurrence division duplex (FDD) for radio transmission. In this age utilizes Frequency Division Multiple Access (FDMA), channel data transmission is $30 \mathrm{KHz}$.

\subsection{Second Generation (2g)}

Second era empowered to give the administrations, for example, instant messages, picture messages and Multimedia messages (MMS) for different cell phone systems. The second era media transmission systems were financially propelled on the Global framework for Mobile correspondences (GSM) standard in 1991.Three essential objectives and advantages of $2 \mathrm{G}$ organizes over their antecedents were that telephone discussions were carefully scrambled; $2 \mathrm{G}$ frameworks were fundamentally progressively effective on the range considering far more noteworthy cell phone infiltration levels; and $2 \mathrm{G}$ presented information administrations for portable, beginning with SMS instant messages. Second era can be partitioned into two models based different access utilized: TDMA based and CDMA based. 2.5G was GPRS which could empower a lot quicker correspondences utilizes bundle exchanging and circuit changing area to give information rate up to $144 \mathrm{kbps}$. In less crowded territories, the flimsier advanced flag may not be adequate to achieve a cell tower. This will in general be a specific issue on $2 \mathrm{G}$ frameworks conveyed on higher frequencies, however is for the most part not an issue on $2 \mathrm{G}$ frameworks sent on lower frequencies.

\subsection{Third Generation (3G)}

Third era innovation is done by the International Telecommunication Union (ITU) in the year 1980 . $3 \mathrm{G}$ correspondence recurrence range between $400 \mathrm{MHz}$ to $3 \mathrm{GHz}$. $3 \mathrm{G}$ innovation endorsed by both the legislature and correspondence organizations collectively. 3G specialized details were made accessible to the open joined the name International Mobile Telecommunications-2000 (IMT-2000). The primary business 3G innovation was propelled by NTT DoCoMo in Japan on 1 October 2001 of W-CDMA. It was at first to some degree constrained in extension; more extensive accessibility of the framework was postponed by evident worries over its dependability. Third era is a lot of models utilized for cell phones and portable media transmission administrations and systems that consent to the IMT-2000. Focal points of utilizing third era in fixed Wireless Internet Access, Wireless Voice Telephony, Video calls, Mobile Internet Access and Mobile TV.

A significant number of the media communications organizations showcase remote versatile Internet benefits as $3 \mathrm{G}$, demonstrating that the promoted administration is given over a $3 \mathrm{G}$ remote system. 
Administrations publicized as 3G are required to fulfill IMT-2000 specialized guidelines, including gauges for dependability and speed (information exchange rates). To meet the IMT-2000 principles, a framework is required to give crest information rates of somewhere around $200 \mathrm{Kbps}$ (about 0.2 Mbps). Notwithstanding, numerous administrations promoted as $3 \mathrm{G}$ give higher speed than the base specialized necessities for a $3 \mathrm{G}$ administration. Ongoing $3 \mathrm{G}$ discharges regularly meant $3.5 \mathrm{G}$ and 3.75G likewise give versatile broadband access of a few Mbps to advanced cells and portable modems in smart phones. CDMA innovation can imparting framework to the IS-95 2G standard. The cell phones are normally CDMA-2000 and IS-95 half and halves.

\subsection{Fourth Generation (4G)}

Expanding development of client request and furthermore the rise of new advancements in the portable correspondences have activated analysts and ventures to concoct exhaustive appearances of the up and coming fourth era $(4 \mathrm{G})$ remote interchanges in versatile innovation. The principle idea in fourth era for the change to the All-IP is to have a typical stage for every one of the advancements that need to grow up until now and to blend with client desires for the many administration to be given. The principle contrast between the All-IP and GSM/3G is that the usefulness of RNC and BSC is presently disseminated to BTS and a lot of servers and doors. Rather than $3 \mathrm{G}$, the new $4 \mathrm{G}$ structure to be set up will endeavor to achieve new dimensions of client experience and multi administration limit by likewise incorporating all the portable advancements that exist (for example GSM, GPRS, IMT2000, Wi-Fi, Bluetooth, ZigBee). 4G innovation information exchange will be a lot quicker and will be more affordable. $4 \mathrm{G}$ will be so savvy for well disposed working capacities adaptability and any ideal administration with sensible nature of administrations (QoS) at whenever, anyplace. Fourth era portable correspondence innovation began in 2010 yet will mass market in around 2015-2016.

Forward age innovation may give top information rate of $1 \mathrm{Gbps}$ for downlink and 500Mbps for Uplink. 4G is considered as Long Term Evolution (LTE) and gives the extra highlights of 3G, similar to remote broadband access, Multimedia Messaging Service (MMS), Video outline, Mobile TV, HDTV content, Digital Video Broadcasting (DVB), insignificant administrations: voice and information. 4G is generally acknowledged that the individual (remote or/and wire) get to systems will interface to center or potentially spine arrange components over the IP convention, the most widely used language of systems administration innovation. Notwithstanding their specific mechanical outlines these remote access systems are relied upon to have a dynamic location task instrument that is equipped for partner a fleeting or extensive IP address to the individual remote interface at the portable terminal, A straightforward IP sending administration that is available over the intelligent end of the IP layer at the versatile terminal and at least one doors at the remote access arrange framework.

IMT-Advanced 4G guidelines will introduce another period of portable broadband correspondences, as per the ITU-R. IMT-Advanced gives a worldwide stage on which to work next ages of intelligent versatile administrations that will give quicker information get to, improved wandering capacities, bound together informing and broadband sight and sound. As per ITU, "ICTs and broadband systems have turned out to be fundamental national framework like transport, vitality and water arranges yet with an effect that guarantees to be significantly increasingly incredible and expansive. These key improvements in remote broadband can drive social and financial advancement, and quicken advance towards accomplishing the United Nations' Millennium Development Goals, or MDGs."

\subsection{Fifth Generation (5G)}

Fifth era innovation is exceptionally quick and dependable to be another portable upset in versatile market. Every one of the administrations of the systems and applications will be gotten to by the single IP as communication, gaming and numerous other sight and sound applications. Through this 5G innovation, worldwide cell innovation goes under one umbrella.5G systems transporters' phenomenal information capacities and has capacity to integrate unhindered call volumes and interminable information communicate with in the up and coming versatile working

\section{CONCLUSION}

Looking at the present and past execution of the remote versatile correspondence framework, it was found that they are as yet helpless to take care of the unending issues of poor inclusion, terrible interconnectivity, adaptability and low quality of administration. The principle favorable position of 
fifth generation will changes the field of remote interchanges area to a totally new highlights and administrations making the world a littler spot to live. For the future age the 5G innovation advances more grounded connections between individuals working in various fields making future ideas of portable correspondences, nanotechnology, distributed computing and network access. In 5G innovations expecting more transmission capacity would not be the appropriate response but rather using the current data transfer capacity through imaginative system configuration is need of great importance. In 5G expecting the system the executives modules need to increasingly astute i.e., psychological programming will make the undertaking of radio asset booking more straightforward.

\section{REFERENCES}

[1] L. Wei and C. Schlegel, "Synchronization requirements for multi-user ofdm on satellite mobile and twopath rayleigh fading channels," Communications, IEEE Transactions on, vol. 43, no. 234, pp. 887-895, 1995.

[2] .M. Tanno, Y. Kishiyama, N. Miki, K. Higuchi, and M. Sawahashi, "Evolved utra-physical layer overview," in Signal Processing Advances in Wireless Communications, 2007. SPAWC 2007. IEEE 8th Workshop on, pp. 1-8, IEEE, 2007.

[3] J. Heiskala and J. Terry, "Ofdm wireless lans: a theoretical and practical guide," 2002.

[4] C. Eklund, R. B. Marks, K. L. Stanwood, and S. Wang, "Ieee standard 802.16: a technical overview of the wirelessman/sup tm/air interface for broadband wireless access," Communica- tions Magazine, IEEE, vol. 40, no. 6, pp. 98-107, 2002.

[5] .M. Morelli, C.-C. Kuo, and M.-O. Pun, "Synchronization techniques for orthogonal frequency division multiple access (ofdma): A tutorial review," Proceedings of the IEEE, vol. 95, no. 7, pp. 1394-1427, 2007.

[6] W. Group et al., IEEE Standard for Local and Metropolitan Area Networks, Part 16: Air Interface for Fixed Broadband Wireless Access Systems, 2004.

[7] .B. Roman, F. Stajano, I. Wassell, and D. Cottingham, "Multi-carrier burst contention (mcbc): Scalable medium access control for wireless networks," in IEEE Wireless Communications and Networking Conference (WCNC), pp. 1667-1672, 2008.

[8] P. Wan, O. Frieder, X. Jia, F. Yao, X. Xu, and S. Tang, "Wireless link scheduling under physical interference model," in IEEE INFOCOM, pp. 838-845, 2011.

[9] .A. Dutta, D. Saha, D. Grunwald, and D. Sicker, "Smack: a smart acknowledgment scheme for broadcast messages in wireless networks," in ACM SIGCOMM Computer Communication Review, vol. 39, pp. 1526, 2009.

[10] K. Wu, H. Tan, Y. Liu, J. Zhang, Q. Zhang, and L. Ni, "Side channel: bits over interference," in ACM MobiCom, pp. 13-24, 2010.

[11] .K. Wu, H. Li, L. Wang, Y. Yi, Y. Liu, Q. Zhang, and L. Ni, "hjam: Attachment transmission in wlans," in INFOCOM, 2012 Proceedings IEEE, pp. 1449-1457, IEEE, 2012.

[12] G. Zhou, C. Huang, T. Yan, T. He, J. A. Stankovic, and T. F. Abdelzaher, "Mmsn: Multi- frequency media access control for wireless sensor networks," in IEEE Infocom, pp. 1-13, 2006

[13] M. Vutukuru, K. Jamieson, and H. Balakrishnan, "Harnessing exposed terminals in wireless networks," in Proceedings of the 5th USENIX Symposium on Networked Systems Design and Implementation, pp. 5972, 2008.

[14] M. Jain, J. Choi, T. Kim, D. Bharadia, S. Seth, K. Srinivasan, P. Levis, S. Katti, and P. Sinha, "Practical, real-time, full duplex wireless," in ACM MobiCom, pp. 301-312, 2011.

Citation: C. Devasenapathi et al., (2019)."Review on Evaluation on Mobile Generation Technology." International Journal of Innovative Research in Electronics and Communications (IJIREC), 6(1), pp.16-19. http://dx.Doi.org/10. 20431/2349-4050.0601003

Copyright: () 2019 Authors. This is an open-access article distributed under the terms of the Creative Commons Attribution License, which permits unrestricted use, distribution, and reproduction in any medium, provided the original author and source are credited. 